\title{
Mucocoele of the sphenoidal sinus as a cause of recurrent oculomotor nerve palsy
}

\author{
GEORGE FRIEDMANN AND SPENCER HARRISON \\ From the Neuro-Otological Department, The National Hospital for Nervous Diseases, \\ Queen Square, London W.C.1.
}

Mucocoeles of the nasal accessory sinuses are commonly found to take origin from the frontal or anterior ethmoidal sinuses. Mucocoeles of the sphenoidal and posterior ethmoidal sinuses are rare conditions and only 60 cases have been described in the literature.

A mucocoele is commonly defined as the accumilation and retention within an accessory sinus of its mucoid secretion, leading to thinning and possible distension and erosion of one or several of its bony walls. When its content is purulent it is generally referred to as a pyocoele. Much controversy has been raised over theaetiology of mucocoeles, but no single factor has found general acceptance. Inflammation and injury, either directly or by scarring, and in rare cases a tumour such as an osteoma may all lead to partial or complete obstruction of the sinoidal ostium and can so cause a mucocoele (Howarth, 1921). Other authors have put forward the theory of a cystic dilatation of one or several mucus glands (Benjamins, 1910), and also congenital factors such as primary narrowing or absence of the sphenoidal outlet and deviation of the nasal septum have been mentioned to explain the origin of this condition (van der Hoeve, 1920; Linthicum, Rand, and Reeves, 1946).

In contrast to the mucocoeles of the frontal and anterior ethmoidal sinuses, the spheno-ethmoidal mucocoeles are not directly visible and therefore difficult to diagnose. A clear history of sinus infections is only rarely present and the rhinological examination is often inconclusive. Nasal discharge or polyposis was found in less than half of the cases and only rarely can a mucocoele be seen bulging forward when examining the nasal cavity or the postnasal space. The development of this condition is slow and protracted and only when the mucocoele expands beyond its natural bony cavity and damages the important adjacent structures are dramatic symptoms likely to occur fairly quickly.

A mucocoele can exert pressure on an optic nerve and chiasma and so cause progressive loss of vision or even acute blindness, it may displace the cavernous portion of the carotid artery laterally and create transient or permanent palsies of the oculomotor nerves or destroy the floor of the sella turcica and simulate an adenoma of the pituitary. A mucocoele produces thus at this late stage of development a variable neurological syndrome and may even simulate a tumour. The diagnosis of a mucocoele is often therefore difficult to establish: in a quarter of the cases in the literature the true nature of the lesion was not recognized until craniotomy was performed, and in one case three craniotomies were undertaken for suspected intracranial lesions (Cody, 1956).

The neurological symptoms of 40 cases of spheno ethmoidal mucocoele, including the present two cases will be reviewed. The term spheno-ethmoidal is $>$ here used in accordance with Lundgren and Olip (1961), who showed that a mucocoele of the sphen oidal or of the posterior ethmoidal sinuses may give rise to similar symptoms and in the late stages it is often impossible to define the exact origin. Most authors report single cases only and so the methods of examination and assessment vary widely and in some cases the diagnosis remains doubtful.

As can be seen from Table 1, the condition was unilateral twice as often as it was bilateral. Headache and pain often localized behind the eye were present in practically all the cases. Loss of vision coming on suddenly or progressively and leading in a few cases to total blindness was present in more than half of the cases. Changes in vision was generally the symptom which made the patient seek medical advice and led to further investigations.

Palsies of the eye movements were present in approximately half of the cases and were predominantly third nerve palsies. Another common finding was exophthalmos, which in the majority of the cases was not marked and in one case was pulsating (O'Shea, 1932). The figures for anosmia are difficult to interpret, because in most of the cases no mention is made of the sense of smell. It seems likely that anosmia would have been found in more than a quarter of the cases had it been searched for. The 
TABLE 1

NEUROLOGICAL SYMPTOMS IN 40 CASES OF SPHENOIDAL MUCOCOELE

\begin{tabular}{lccc}
\hline \multicolumn{1}{c}{ Cranial nerves affected } & Unilaterally & Bilaterally & Total \\
\hline I Olfactory & 7 & 3 & 10 \\
II Optic & 16 & 7 & 23 \\
III Oculomotor & 15 & - & 15 \\
IV Trochlear & 2 & - & 2 \\
VI Abducent & 4 & - & 4 \\
Other symptoms & & & \\
$\quad$ Facial pain & & & 38 \\
$\quad$ Exophthalmos & & & 12 \\
$\quad$ Pituitary hypofunction & & & 15 \\
Nasal symptoms & & \\
\hline
\end{tabular}

(Hajek, 1910; Kan, 1920; Horgan, 1921; Stieren and McKee, 1932; Berendes, 1939; Blanc, Lévy, and Wertheimer, 1939; Bilchick, 1940; Labayle, 1949; Everberg, 1955; Achslogh and Gottlob, 1957; MacCarthy, Lillie, Daily, Hollenhorst, and Holman, 1957; Neffson, 1957; Petit-Dutaillis, 1958; Maxwell and Hill, 1959; Heitzman and Ferguson, 1966).

complication of compression of the pituitary is rare, though again pituitary function was tested only in one case when a pituitary adenoma was suspected (Escher, 1963). It is remarkable that nasal symptoms were present in less than half of the cases in the literature, most of which were undoubtedly advanced.

Whereas the visual complications of sinus disease have been well documented, little has been written since the study of Dimsdale and Phillips (1950) on the subject of cranial nerve palsies in sinus affections and it seems therefore justified to discuss the following two cases with isolated intermittent oculomotor nerve palsies.

\section{CASE 1 (A34324)}

A 48-year-old male cook of Spanish origin was admitted to the National Hospital because of pain in his left upper face and jaw for one month, and drooping of his left upper eyelid for a fortnight.

He had been in good health throughout his life and there was no family history of diabetes, hypertension, or neurological disorder. Apart from occasional colds he had no history of sinus trouble or respiratory allergy.

Two years previously the first episode of pain occurred behind his left eye, followed by diplopia and ptosis of the left eyelid, and lasted one month clearing up spontaneously without treatment. Since then the patient had been quite well until the present episode when he suddenly developed, three weeks before his admission, severe pain in his left forehead, left eye, and upper jaw, and inside his nose. The pain was extremely severe, of deep aching quality, not relieved by aspirin, interfering with sleep and was followed after one week by a complete left ptosis.

On examination he was fully orientated. There was a total left anosmia previously unnoticed by the patient and a complete extra-ocular third nerve palsy. The pupil, however, was not dilated and reacted to light. The 4th and 6th nerve function was normal. On both sides vision, fundi, and fields were normal. The blood pressure was $160 / 90 \mathrm{~mm} \mathrm{Hg}$ but no other pathological findings were noted. Blood count, blood sugar, and WR were all normal. The cerebrospinal fluid was clear, colourless, and under normal pressure, protein $(45 \mathrm{mg} / 100 \mathrm{ml}$.) and sugar were within normal limits, and no cells were present. No abnormality was found on otolaryngological examination and the left antrum washout fluid was clear.

RADIOlOGICAL EXAMINATION Skull Some abnormal shadowing was seen in the region of the sphenoidal and posterior ethmoidal sinuses and thickening of the mucosal lining of both antra (Fig. 1). Anteroposterior (Fig. 2) and lateral (Fig. 3) tomograms showed the presence of a spherical mass about $3.2 \mathrm{~cm}$ in diameter, situated almost in the midline but more on the left than on the right extending about $2 \mathrm{~cm}$ to the left and $1 \mathrm{~cm}$ to the right, which in lateral projection occupied most of the sphenoidal and posterior ethmoid sinuses. The floor of the sphenoid and posterior wall of the clivus were intact.

On left carotid angiogram the cavernous portion of the internal carotid was in its proximal part displaced backwards and laterally (Fig. 4).

$X$-ray diagnosis Mucocoele of the sphenoidal sinuses perhaps invading the posterior ethmoidal sinuses also.

EXPLORATION OF SPHENOIDAL SINUSES AND POST ETHMOIDAL SINUSES VIA LEFT PATTERSON'S APPROACH (Harrison, 1969) The mucous membrane of the right sphenoidal sinus was found to be swollen, a large bulging mucocoele was

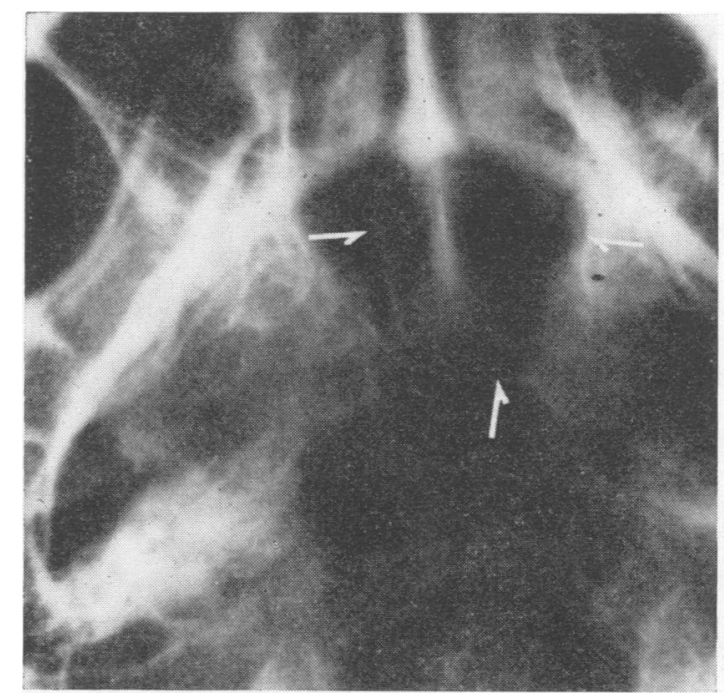

FIG. 1. Abnormal shadowing in the region of the sphenoidal and posterior ethmoidal sinuses. 


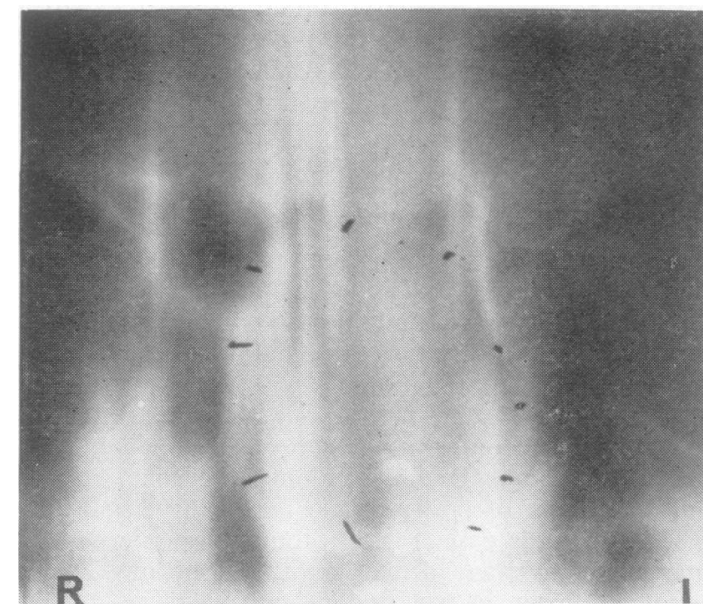

FIG. 2. Anteroposterior tomogram. A spherical mass extends chiefly to the left of the midline affecting the sphenoidal and posterior ethmoidal sinuses.

found replacing the left sphenoidal sinus. Abundant viscous mucus and yellow fluid with inspissated debris escaped. when the anterior wall of the sac was opened. The lining was removed and the large cavity was packed with medicated gauze brought out through the nose.

The tissue removed consisted mainly of tall columnar cells, many being goblet cells supported on oedematous connective tissue: this was infiltrated by moderate numbers of plasma cells and polymorphs most of which were eosinophils. Acini lined by columnar cells containing mucin occurred in the connective tissue as well as occa-

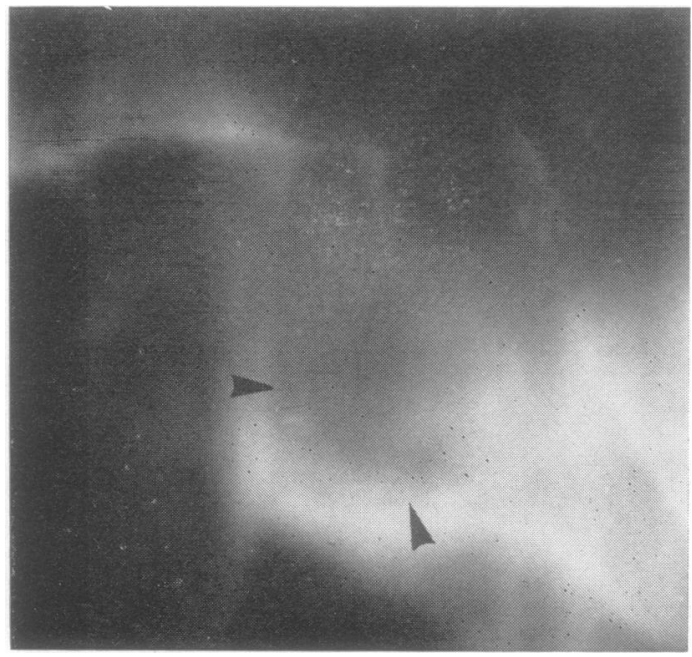

FIG. 3. Lateral tomogram. The mass in the posterior sinuses is demonstrated again.

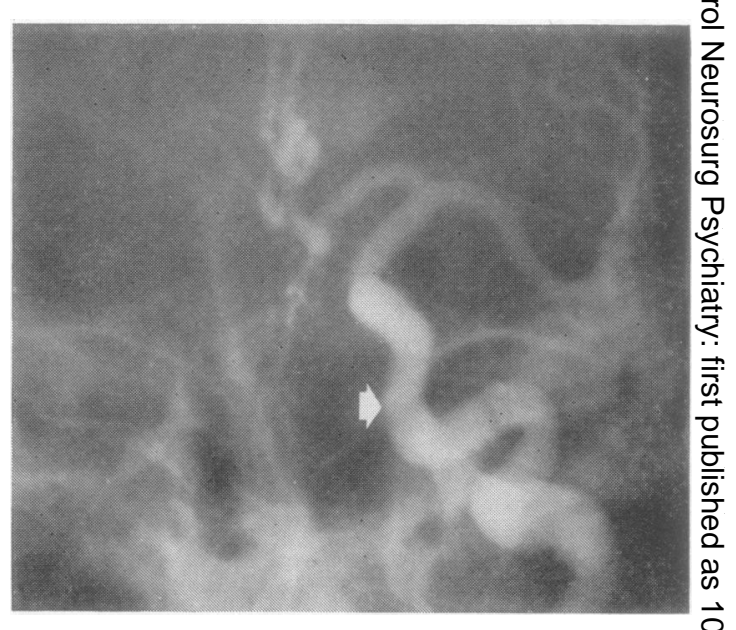

FIG. 4. Left carotid angiogram. The cavernous portion of the artery is displaced backwards and laterally.

sional lymphoid follicles. Portions of bone also could bect seen in the tissue where the histological picture was thatt of subacute or chronic inflammatory reaction. Bacter logical examination and culture were negative.

Three days after the operation the headache and third nerve palsy had improved and a week later was free from pain, the ptosis had cleared up completely and the mobility of the eyes was full on both sides.

The patient has been followed up regularly ahdremained symptom free. He was last seen two yesiss after the operation.

CASE 2 (3727)

A 55-year-old male advertising agent was seen as ano out-patient in the National Hospital complaining that 14 months previously he began to suffer from severe pain in his head and behind the left eye regularly at: 1 p.m. every day, so that he could almost set a clock 3 by it. After eight weeks the severity of pain gradually? improved. A radiograph taken at the time showed an opaque left antrum, but the patient refused further treatment because of the spontaneous disappearance of the pain. Two weeks previously, before his out-patiento attendance, a severe intermittent throbbing pain behind the left eye reoccurred after a cold and spread to the side of the nose. Three days after the onset of the pain he found it increasingly difficult to open his left eye and 3 he noticed diplopia on looking upwards, downwards, and to the right.

On clinical examination the only abnormalities found $\frac{7}{8}$ were a marked but incomplete ptosis, a complete palsy of the extra-ocular muscles innervated by the left 3rdn nerve, and a pupil reacting sluggishly to light. After one week the pain disappeared but the diplopia and $\tilde{O}^{-}$ ptosis persisted. He was thus admitted a week later for ${ }_{\mathrm{W}}^{N}$ further investigation, but by that time he was alreadyo 
symptom free and showed only a slight left ptosis. Otolaryngological examination revealed a deformity of the nasal septum and the presence of mucopus far back on the left side of his nose.

RADIOLOGICAL EXAMINATION Swelling of the lining mucosa of the left antrum was reported, the ethmoid sinuses showed lack of translucency due to mucosal changes. The sphenoid sinuses were partially opaque and their postero-superior walls could not be outlined. The entire sellar region was decalcified, particularly the anterior part of the floor. Lipiodol was introduced into the nose (after Proetz) and the maxillary sinuses and the anterior and middle ethmoids accepted the fluid but only the right sphenoidal sinus, which was outlined as a narrow slit anteroposteriorly. The left sphenoidal sinus was hazy and its outline was not clearly demarcated (Fig. 5). A left carotid angiogram showed that the carotid syphon was displaced laterally in a smooth curve.

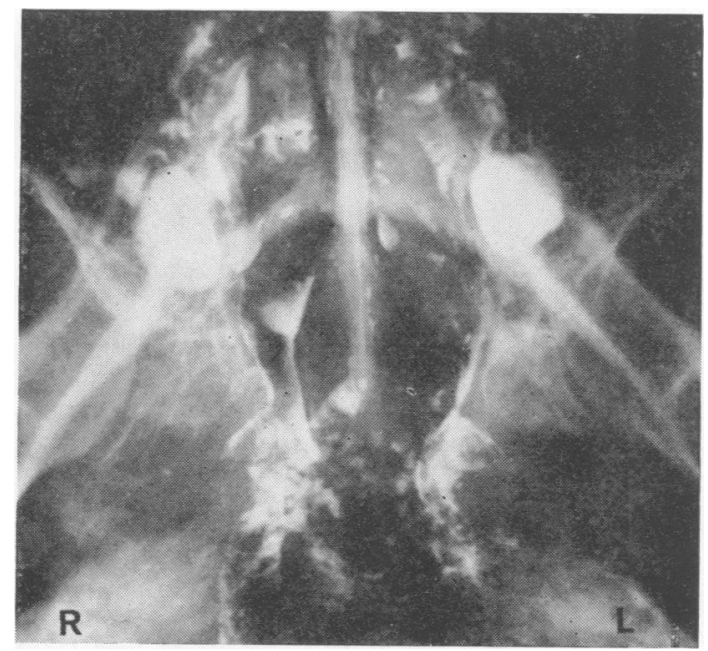

FIG. 5. Lipiodol has not filled the left sphenoidal sinus and the right sinus is reduced to a narrow slit.

$X$-ray diagnosis A left parasellar space-occupying lesion situated in the region of the left sphenoidal sinus, expanding laterally and pressing upon the carotid syphon.

EXPLORATION OF SPHENOIDAL SINUS In order to obtain access to the sphenoidal sinus a preliminary resection of the nasal septal cartilage of the nose was performed. As soon as the sphenoidal sinus was opened a large quantity of almost clear thick glairy fluid (half a test tube full) gushed forth which had obviously been under considerable pressure. This was followed by brisk haemorrhage and after this had been controlled the mucosa and blood clot remaining in the sinus were seen to be pulsating strongly, presumably due to the fact that the mucocoele had eroded sufficient bone to expose a considerable area of dura.
Reporting after 15 months follow-up the patient was completely symptom free.

\section{DISCUSSION}

In both patients unilateral facial pain and pain behind the eye were the initial symptoms starting one to two years before hospital admission. The headache was extremely severe and disabling. The character and localization of the pain seem typical of trigeminal pain caused by compression or irritation, rather than purely referred pain from the sphenoidal sinus.

Both patients suffered a transient 3rd nerve palsy, characterized by drooping of the eyelid and diplopia. The first patient developed a further episode which failed to clear up spontaneously. No damage to the optic nerve was observed and reaction of the pupils to light was preserved in both cases.

One patient developed unilateral anosmia, though the mucocoele did not obstruct the nasal passages, and the anosmia, which persisted after the operation, was probably due to damage to the olfactory organ. No other nasal symptoms developed in this patient, in contrast with the second patient who showed signs of acute sinus infection.

It is unusual to find a sphenoidal mucocoele as the underlying cause of a recurrent 3rd nerve palsy and we could trace only eight further cases in the literature. Their characteristics are shown in concise form in Table 2.

The cases of Dimsdale and Phillips (1950) were diagnosed as sphenoiditis, but they also had the characteristics of a mucocoele and none of them suffered from an acute infection. In all the other cases the diagnosis of a mucocoele was made.

From Table 2 a clearly defined clinical entity crystallizes itself. The initial symptom is nearly always attacks of retro- and supraorbital pain of severe character, radiating to forehead and occipital regions, and lasting from several hours to several days. After a few months the attacks grow even more severe and the interval between them shorter. At this stage ptosis, diplopia, and blurring vision occur in no fixed order. These episodes would often last several days or weeks and then clear up spontaneously together with the remission of pain.

In five patients oculomotor palsy was accompanied by loss of vision. It is interesting to note that one patient had three attacks and another as many as four attacks of oculomotor palsy before visual loss occurred. In the remaining five patients no visual symptoms were observed. It may be that these patients were successfully treated at an earlier stage of their disease or, more likely, that 
TABLE 2

CASES IN THE LITERATURE

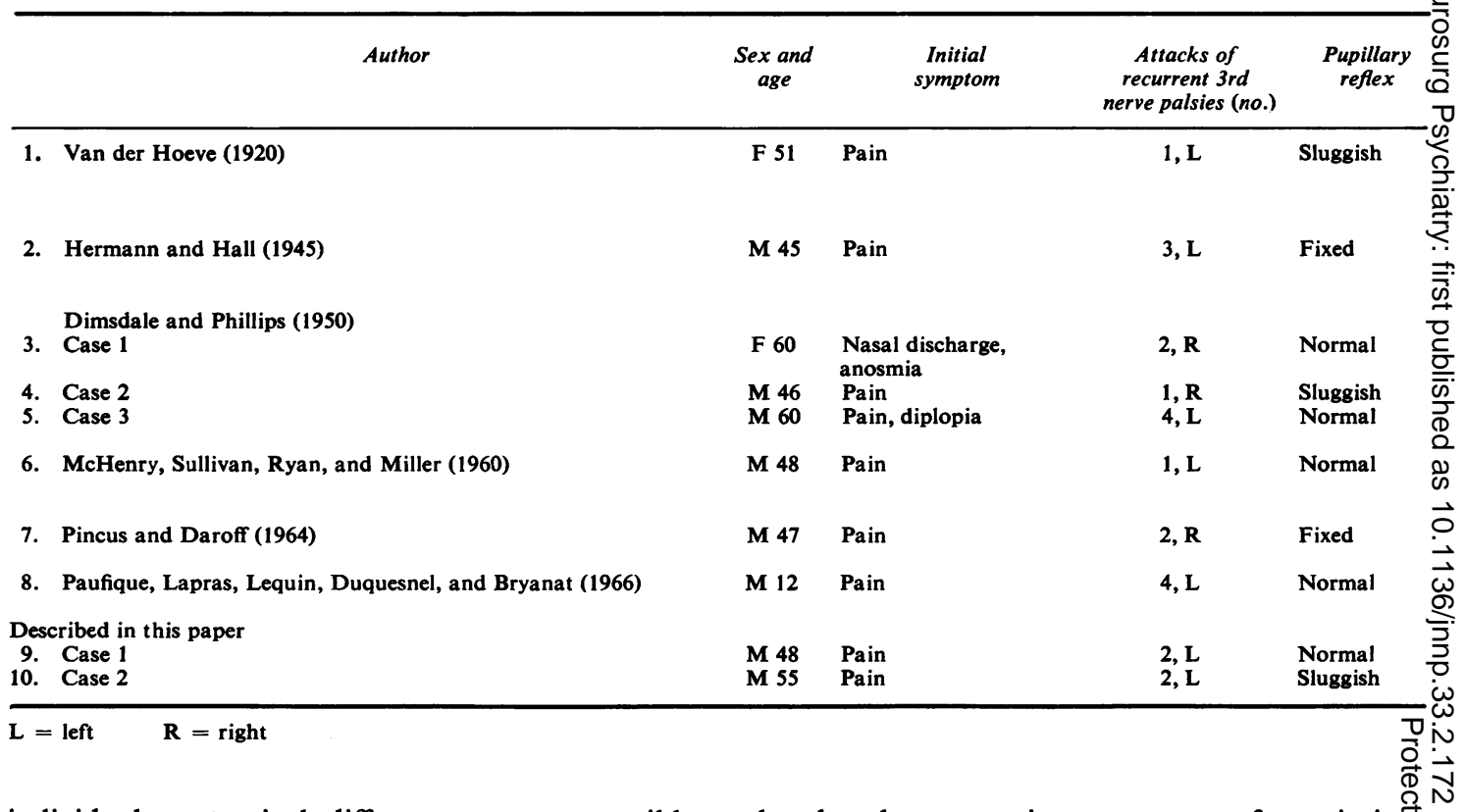

individual anatomical differences are responsible.

It is pertinent that in eight cases the pupillary reaction to light was preserved, a finding that has been reported to be typical of diabetic ophthalmoplegia, whereas in ophthalmoplegia caused by aneurysms and tumours the pupillary reaction is usually abnormal (Rucker, 1958; Goldstein and Cogan, 1960).

Anosmia was found in three cases, and was in one bilateral; testing of smell is however mentioned in only five cases.

A history of sinus disease was present in four, but only in two of them was the rhinoscopic examination abnormal. Mucopus was present in one and nasal polypi in the other.

The absence of pathological findings on rhinological examination, the complete recovery between attacks and the large number of 3 rd nerve palsies of unknown aetiology may explain why this condition is seldom diagnosed at an early stage.

The syndrome of severe unilateral facial pain with recurrent 3rd nerve palsy is typical of ophthalmoplegic migraine (Walsh and O'Doherty, 1960), but before this diagnosis is made a sphenoidal mucocoele should be excluded. Jefferson (1947) found that 55 aneurysms out of total 158 caused isolated paralysis of the oculomotor nerve, but in such a case the recovery after a single episode is never as complete as in ophthalmoplegic migraine or in mucocoele. Oculomotor nerve paralyses may also be the presenting symptom of a pituitaigy adenoma (Symonds, 1962; Francois and Neetees,1968) and patients affected by a mucocoele hayes undergone craniotomy, the condition having beenc mistaken for that caused by a pituitary tumow. The difficulty or even impossibility of distinguishig in some rare cases between a mucocoele and an aberrant cystic pituitary tumour such as craniopharyngioma has been pointed out by Schüller (1932) and Lundgren and Olin (1961).

A history of sinus infection and the presence of pus or polypi on nasal examination will favour the diagnosis of a mucocoele. The finding of unilatera or bilateral anosmia will also support this diagnosis 3 Anosmia is mentioned in more than a quarter of the? cases of mucocoele and is seldom associated with other forms of third nerve palsies.

Confirmation of the diagnosis will always be radiological. On plain films of the skull the sphenoidal sinus will usually be opaque, but may appear radiolucent if the combination of bone destruction and fluid accumulation result in a less dense image. 3 Wide expansion of the sinus may be associated witho hypertranslucency (Bloom, 1965). Tomography? shows loss of marginal scalloping, destruction of bone, and changes in the adjacent structures (Simon and Tingwald, 1955; Palubinskas and $\widehat{N}$ Davies, 1959). Lateral displacement of the cavernous portion of the internal carotid artery, best seen ins the anteroposterior projection, is highly significant 
TABLE 2-continued

CASES IN THE LITERATURE

\begin{tabular}{|c|c|c|}
\hline Other neurological symptoms & Nasal symptoms & $\begin{array}{l}\text { Recovery after } \\
\text { operation }\end{array}$ \\
\hline $\begin{array}{l}\text { Pain in } L \text { occipital region for } 3 \text { yr. } L \text { amaurosis and optic atrophy, } L \text { exophthalmos. } \\
\mathbf{R} \text { eye: variable loss of visual acuity, central scotoma }\end{array}$ & Absent & $\begin{array}{l}\text { Recovery of right visual } \\
\text { acuity, disappearance of } \\
\text { pain and exophthalmos }\end{array}$ \\
\hline $\begin{array}{l}\text { Attacks of pain for } 18 \mathrm{~m} \text {, radiating in } L \text { side of face and occipital region, associated } \\
\text { with seborrhoeic dermatitis. Visual acuity in } L \text { eye diminished to light perception, } \\
L \text { anosmia }\end{array}$ & Absent & $\begin{array}{l}\text { Full, except pupillary } \\
\text { reaction }\end{array}$ \\
\hline $\begin{array}{l}\text { Intermittent pain in } R \text { side of forehead for } 5 \mathrm{~m} \text {. } L \text { visual acuity } 6 / 36 \text { and } R 6 / 12 \text { corrected. } \\
\text { Visual fields } L \text { hemianopic temporal defect. Bilateral anosmia } \\
\text { Attacks of shooting pain in } R \text { temple for } 6 \mathrm{~m} \text {. Weakness of } R \text { superior oblique muscle } \\
\text { Intermittent dull aching pain in } L \text { temple for } 9 \mathrm{~m}\end{array}$ & $\begin{array}{l}\text { Nasal discharge for } \\
\text { many years, until } 5 \text { yr } \\
\text { Absent } \\
\text { Nasal injury } 35 \text { yr ago } \\
\text { Polypectomy }\end{array}$ & $\begin{array}{l}\text { Full } \\
\text { Full } \\
\text { Full }\end{array}$ \\
\hline Intermittent headache behind $L$ eye and in $L$ frontal region for $3 \mathrm{yr}$ & $\begin{array}{l}\text { Bilateral ethmoidecto- } \\
\text { mies and several } \\
\text { polypectomies }\end{array}$ & Full \\
\hline $\begin{array}{l}\text { Intermittent throbbing headache for } 2 \text { yr behind } \mathbf{R} \text { eye associated with nausea, } \\
\text { vomiting, photophobia, and small } \mathbf{R} \text { central scotoma }\end{array}$ & Absent & Full \\
\hline $\begin{array}{l}\text { Intermittent } L \text { supraorbital pain for } 4 \text { yr associated with vomiting, and early } L \text { opt ic } \\
\text { atrophy }\end{array}$ & Absent & Full \\
\hline $\begin{array}{l}\text { Intermittent pain in } L \text { upper face for } 2 \mathrm{yr} \text {. Left anosmia } \\
\text { Intermittent } L \text { retroorbital pain for } 14 \mathrm{~m}\end{array}$ & $\begin{array}{l}\text { Absent } \\
\text { Mucopus in L. nostril }\end{array}$ & $\begin{array}{l}\text { Full } \\
\text { Full }\end{array}$ \\
\hline
\end{tabular}

of an extracerebral mass lying within or involving the medial part of the cranial fossa (Bull and Schunk, 1962; Nelson, Holloway, Kara-Eneff, and Goldenberg, 1967). If the distinction between a hypophyseal tumour and a sphenoidal mucocoele proves radiologically difficult, puncture of the sphenoidal cavity and injection of Lipiodol to outline the cyst may be undertaken (Hermann and Hall, 1945; Küstner, 1952; Libersa and Cecille, 1962; Escher, 1963).

\section{PATHOGENESIS}

In one of our patients the tissue removed during the operation was histologically examined and showed the signs of chronic non-specific inflammation. This is in accordance with cases in the literature in which histological examination was undertaken. The colour and viscosity of the fluid retained in the cyst varies greatly from the most usual thick and mucoid material to thin and yellow or chocolate brown fluid depending on the content of pus or blood. Microscopical examination has often shown cells and cholesterol crystals, but as a rule no organisms have been found. The fluid is usually found to be under considerable pressure during operation. This raised pressure of the cyst contents can lead to extensive destruction of the surrounding bony walls, well described in one case which came to necropsy (Linthicum et al., 1946) in which the mucocoele had destroyed the bony wall of the sphenoid sinus, flattened the posterior clinoid process and the groove of the sella turcica, pushed the hypophysis to the right of the midline, and compressed and flattened the left optic nerve.

Destruction of the bony walls has also been observed in cases which had undergone craniotomy and the pulsating dura was often directly seen during endonasal operations as in our second case. The isolated affection of the oculomotor nerve observed in our cases explains itself anatomically. When pituitary adenomata, as pointed out by Francois and Neetens (1968), extend backwards and upwards the first nerve to be stretched in its dural sheet as it penetrates the cavernous sinus will be the oculomotor nerve. The fact that the paresis is often intermittent at an early stage is likely to be due to changing congestion and pressure of the mucocoele, which would stretch the dural sheet which contains the oculomotor nerve to a variable degree. In this context, it is interesting to remember that the pupillary reaction to light was preserved in eight out of 10 cases suffering from oculomotor palsy (Table 2).

In their extensive histopathological study of a case of diabetic ophthalmoplegia with preserved pupillary reaction, Dreyfus, Hakim, and Adams (1957) thought the lesion was compatible with an incomplete ischaemic neuropathy. The conservation of the pupillary response is explained by the ob- 
servation that the pupillary fibres travel between the middle of the cavernous sinus and the brain-stem at and around the surface of the oculomotor nerve (Sunderland and Hughes, 1946). This peripheral position makes the pupillary fibres most vulnerable to external pressure but provides them with a better blood supply than the central part of the nerve in the case of ischaemia.

By analogy, the normal pupillary response in the majority of our cases makes us think that the ophthalmoplegia was not caused by direct pressure on the third nerve, but that the pressure of the mucocoele disturbed the circulation in the nutrient vessels and that an ischaemic neuropathy was responsible for the palsy. Bearing in mind that the oculomotor nerve and the first two branches of the trigeminal nerve are often separated from the sphenoidal cavity by a bony wall only as thick as an eggshell (Onodi, 1914; Sluder, 1918) it is astonishing how rarely an affection of the sphenoidal sinus causes cranial nerve palsies. Individual congenital factors, such as a very large sphenoidal sinus, a dehiscence in its bony wall or a small cavernous sinus, may be needed to provide the requirements for the development of this condition.

\section{TREATMENT}

The treatment of the sphenoidal mucocoeleisalways surgical, the posterior cells of the ethmoidal labyrinth and the anterior wall of the sphenoidal sinus should be removed, the mucocoele opened widely, and the lining removed where possible. In extensive mucocoeles a simple marsupialization of the mucocoeleinto the posterior nasal fossa may be indicated in order to allow for drainage and remove pressure, and it may be necessary to avoid injury to the lining in view of the damage to the optic nerve and the cavernous sinus (Hazeyama, 1967). External ethmoidal, transmaxillary, transeptal, and endonasal approaches have been described, all with satisfactory results. In all cases operated upon dramatic and durable relief of pain was achieved, starting a few days after operation.

When exophthalmos was present, it regressed rapidly as did the paralysed oculomotor nerves after operation in practically all cases. It was not possible to judge from the literature if the patients with anosmia regained their sense of smell, or if anosmia persisted after operation as in one of the present cases. Of the 23 patients who suffered unilateral or bilateral loss of vision (Table 1), 10 recovered completely and seven partially after operation, whereas in six the symptoms were unchanged. The chances of recovery are naturally diminished in patients with long-standing or complete loss of vision. But, as shown by the two 은 cases of Lundgren and Olin (1961), permanent远 blindness can persist after only a few days of symptoms despite operative treatment; on the other hand, severe impairment of vision of yearso duration can also disappear after operation.

When the pressure is relieved the bone commencess to regenerate and an eroded sella turcica wile reform within a few months (Dimsdale and Phillips 1950). After a successful operation the free drainage of the sphenoidal sinus can be demonstrated radio $\vec{\Rightarrow}$ logically; a contrast medium instilled in the noseo will readily flow into the sphenoidal sinus when the head is tilted backwards (Lundgren and Olin, 1961).

There are no contraindications to operative treatment and the post-operative course was practi - s cally always uneventful. In some patients howevero nasal discharge and post-nasal drip may continue for a long time afterwards.

Despite an apparent recovery after an attack of̂ intermittent third nerve palsy, the mucocoele can continue to expand and cause irreversible opties atrophy. Early treatment of this condition is theze fore at times of some urgency.

SUMMARY

The neurological symptoms of 40 cases of sphenoidat mucocoele are listed and two cases of recurrente. oculomotor nerve palsy caused by a sphenoifate mucocoele are described.

Symptomatology, differential diagnosis, and pathogenesis of this condition are discussed and early surgical treatment is emphasized.

We wish to express our gratitude to Dr. J. N. Bla脶 and Dr. D. H. Brinton who kindly allowed us to studø their cases and also to thank Dr. Blau for his helpfut comments on the manuscript. We are particularly grateful to Dr. J. W. D. Bull for his comments and per mission to publish the radiographs and also to Professef J. N. Cumings and Dr. W. G. P. Mair for the pathological investigations.

\section{REFERENCES}

Achslogh, J., and Gottlob, F. (1957). Polype et mucocèle intracrânieß Acta neurol. belg., 57, 303-317.

Benjamins, C. E. (1910). Mucocele des sinus sphenoidalis. Arch. Lar. Rhin. (Berl.), 24, 353-365.

Berendes, J. (1939). Úber eine Mucocele der Keilbeinhöhle. Arch̆ Ohr -, Nas -, u. Kehlk.-Heilk., 146, 189-193.

Bilchick, E. B. (1940). Disease of the sphenoidal sinus. With a repoof of a case of cyst of the sphenoid sinus. Arch. Otolaryng., $3 \bar{z}$ 1031-1038.

Blanc, Dechaume, J., Lévy, Mounier-Kuhn, P., and Wertheimer, $\boldsymbol{P}$. (1939). Mucocèle du sphénoide à évolution endocraniennÀ Ann. Oto-laryng. (Paris.), 58, 320-324.

Bloom, D. L. (1965). Mucoceles of the maxillary and sphenoid sinuseso Radiology, 85, 1103-1109. 
Bull, J. W. D., and Schunk, H. (1962). The significance of displacement of the cavernous portion of the internal carotid artery. Brit. J. Radiol., 35, 801-814.

Cody, C. C. (1956). An unusual case of sphenoid abscess. Arch. Otolaryng., 63, 199-202.

Dimsdale, H., and Phillips, D. G. (1950). Ocular palsies with nasal sinusit is. J. Neurol. Neurosurg. Psychiat., 13, 225-236.

Dreyfus, P. M., Hakim, S., and Adams, R. D. (1957). Diabetic ophthalmoplegia. Arch. Neurol. Psychiat., 77, 337-349.

Escher, F. (1963). Mucocèle sphénoïdale avec syndrome hypophysaire. Conf. neurol. (Basel), 23, 305-308.

Everberg, G. (1955). Retrobulbar neurit is due to cyst of sphen oid sinus. Acta Oto-laryng. (Stockh.), 45, 492-497.

Francois, J., and Neetens, A. (1968). Oculomotor paralyses and tumours of the pituitary gland. Confin. neurol. (Basel), 30, 239-252.

Goldstein, J. E., and Cogan, D. G. (1960). Diabetic ophthalmoplegia with special reference to the pupil. Arch. Ophthal., 64, 592-600.

Hajek, M. (1910). Mucocèle der Keilbeinhöhle, kompliziert durch Neuritis optica. Operation, Heilung. Mschr. Ohrenheilk., 44, 331-338.

Harrison, M. Spencer. Patterson's external approach in surgery of nose and sinuses. E.E.N.T. Digest, January 1969.

Hazeyama, F. (1967). Uber Mukozelen der Keilbeinhöhle, ihre differential diagnost ische Bedeutung and operative Behandlung. Z. Laryng. Rhinol., 46, 298-301.

Heitzman, E. R., and Ferguson, J. H. (1966). Left frontal headache with blurred vision. N.Y. St.J.Med., 66,976-978.

Hermann, K., and Hall, I. S. (1945). Sphenoidal mucocele as a cause of the 'ophthalmoplegic migraine syndrome'. Trans. ophthal. Soc. U.K., 64, 154-164.

Hoeve, J. van der (1920). Mucocèle der Keilbeinhöhle und hinteren Siebbeinzellen mit Atrophie des Sehnerven. Z. Augenheilk., 43, 223-242.

Horgan, J. B. (1921). Abducens paralysis secondary to chronic hyperplast ic spheno-ethmoidit is. J. Laryng., 46, 542-543.

Howarth, W. G. (1921). Mucocele and pyocele of the nasal accessory sinuses. Lancet, 2, 744-746.

Jefferson, G. (1947). Isolated oculomotor palsy caused by intracranial aneurysm. Proc. roy. Soc. Med., 15, 419-432.

Kan, P. Th. L. (1920). Mukokele des Siebbeines und der Keilbeinhöhle. Mschr. Ohrenheilk., 54, 1136.

Küstner, W. (1952). Zur Diagnostik der Keilbeinhöhlen-Mucocele. H.N.O. (Berl.), 3, 303-305.

Labayle, (1949). Mucocéle du sphénoïde. Ann. Oto-laryng. (Paris), 66, 683-685.

Libersa, Cl. and Cecille, J. P. (1962). A propos d'une mucocele du sinus sphenoidale. J. Franc. Oto-rhino-laryng., 11, 404-412.

Linthicum, F. H., Rand, C. W., and Reeves, D. L. (1946). Mucocele of the sphenoid sinus. Report of a case with autopsy findings. J. Neurosurg., 3, 444-453.

Lundgren, A., and Olin, T. (1961). Muco-pyocele of sphenoidal sinus or posterior ethmoidal cells with special reference to the apex orbitae syndrome. Acta Oto-laryng. (Stockh.), 53, 61-79.
MacCarthy, C. S., Lillie, J. C., Daily, D. D., Hollenhorst, R. W., and Holman, C. B. (1957). Blindness secondary to unusual cyst of the sphenoid sinus. Arch. Ophthal., 58, 747-750.

Maxwell, J. H., and Hill, B. J. (1959). The diagnosis of chronic inflammatory lesions of the sphenoid sinus. Ann. Otol., 68, 411-452.

McHenry, L. C., Sullivan, J. F., Ryan, H. J., and Miller, D. (1960). Mucocele of the sphenoidal sinus. A benign lesion simulating a malignant process. New Engl.J. Med., 262, 549-551.

Neffson, A. H. (1957). Mucocele of the sphenoid sinus. Arch. Otolaryng., 66, 157-164.

Nelson, D. A., Holloway, W. J., Kara-Eneff, S. C., and Goldenberg, H. I. (1967). Neurological syndromes produced by sphenoid sinus abscess with neuroradiologic review of pituitary abscess. Neurology (Minneap.), 17, 981-987.

Onodi, L. (1914). The rhinogenic and otogenic lesions of the third, fourth, fifth and sixth cranial nerves. J. Laryng., 29, 304-311, 360-372.

O'Shea, H. V. (1932). Pulsating exophthalmos due to sphenoidal sinus mucocele. Lancet, 1, 1253-1254.

Palubinskas, A. J., and Davies, H. (1959). Roentgen features of nasal accessory sinus mucoceles. Radiology, 72, 576-584.

Paufique, L., Lapras Cl., Lequin, Mme., Duquesnel, J., and Bryunat, M. (1966). Mucocèle sphenoïdale et paralysies oculaires récidivantes. Bull. Soc. Ophthal.(Paris), 66, 876-880.

Petit-Dutaillis, D., Schiff-Wertheimer, S., Aubry, M. et Metzger, J. (1958). Syndrome de compression d'un nerf optique par une mucocèle sphénoïdale latente. Intervention par voie paralatéro-nasale. Importance des signes radiologiques pour le diag nostic. Neurochirurgie, 4, 81-94.

Pincus, J. H., and Daroff, R. B. (1964). Sphenoid sinus mucocele. A curable cause of the ophthalmoplegic migraine syndrome. J. Amer. med. Ass., 187, 459-460.

Rucker, C. W. (1958). Paralysis of the third, fourth and sixth cranial nerves. Amer. J. Ophthal., 46, 787-794.

Schüller, A. (1932). Sphenoidale Mucocele oder zyst ischer Hypophysentumor. Mschr. Ohrenheilk., 66, 166-172.

Simon, H. M., Jun., and Tingwald, F. R. (1955). Syndrome associated with mucocele of the sphenoid sinus. Report of two cases and their radiographic findings. Radiology, 64, 538-545.

Sluder, G. (1918). Concerning Some Headaches and Eye Disorders of Nasal Origin: Henry Kimpton: London.

Stieren, E., and McKee, G. J. (1932). Complete unilateral ophthalmoplegia externa due to ethmosphenoiditis. Recovery after ethinosphenoid exenteration. Penn. med.J., 36, 84-85.

Sunderland, S., and Hughes, E. S. R. (1946). The pupillo-constrictor pathway and the nerves to the ocular muscles in Man. Brain, 69, 301-309.

Symonds, C. (1962). Ocular palsy as the presenting symptom of pituitary adenoma. Bull.Johns. Hopk. Hosp., 3, 72-82.

Walsh, J. P., and O'Doherty, D. J. (1960). A possible explanation of the mechanism of ophthalmoplegic migraine. Neurology, 10, 1079-1084. 